\title{
Transapical cannulation for surgical repair of chronic type B aortic dissection
}

\author{
Shinsuke Kotani ${ }^{1}$ and Minoru Tabata ${ }^{1}$ \\ ${ }^{1}$ Tokyo Bay Urayasu Ichikawa Iryo Center
}

December 7, 2021

\begin{abstract}
Open surgery for chronic type B aortic dissection has been shown to have considerable risks of cerebrovascular complications. Because retrograde perfusion is a potential cause of intraoperative cerebrovascular events, we report our transapical cannulation strategy for descending aorta replacement in chronic type B aortic dissection repair with circulatory arrest. This technique provides an easy and quick establishment of cardiopulmonary bypass by way of a left thoracotomy, and prevention of cerebrovascular event. Transapical cannula can be also used as a vent to ensure a bloodless field during proximal anastomosis and to prevent extension of left ventricle during rewarming. Transapical cannulation is a useful option in open repair of the descending aorta for chronic type B aortic dissection by way of left thoracotomy.
\end{abstract}

\section{Introduction}

Open repair for treatment of chronic type $\mathrm{B}$ aortic dissection (CBAD) is challenging. Replacement of the descending aorta for treatment of CBAD via a left thoracotomy often requires circulatory arrest during proximal anastomosis. It is important to devise a cardiopulmonary bypass (CPB) strategy to prevent various complications, including cerebrovascular events. We herein describe our transapical cannulation strategy for descending aorta replacement in CBAD repair.

\section{Technique}

The patient is placed in the right lateral position. A left lateral thoracotomy is performed through the fourth or fifth intercostal space. Before manipulation to the descending aorta, the pericardium is incised and the location of the apex is confirmed by transesophageal echocardiography. Two pairs of pledget-supported 2-0 monofilament polypropylene sutures are placed on the apex, avoiding injury to the left anterior descending artery. An arterial cannula is inserted into the ascending aorta using the echocardiogram-guided Seldinger wire technique (Video 1). CPB is established by arterial cannulation via the apex and left femoral artery with venous drainage via the left femoral vein (Figure 1A). Once the bladder or rectal temperature has been cooled to $25^{\circ} \mathrm{C}$, potassium chloride is systemically administered instead of cardioplegia for myocardial protection during circulatory arrest. After clamping of the distal descending aorta, upper body perfusion is discontinued (circulatory arrest) and lower body perfusion is started via the left femoral artery. Retrograde cerebral perfusion is initiated using Takamoto's technique. ${ }^{1}$ An apical cannula in the ascending aorta is used as a vent to ensure a bloodless operative field during proximal anastomosis (Figure 1B). After the proximal anastomosis using a branched vascular prosthesis, upper body perfusion is resumed through the branch of the prosthetic graft. The apical cannula is pulled back to the left ventricle and used as a ventricular vent during rewarming (Figure 1C). Distal anastomosis is performed after dividing the membrane separating the true and false aortic lumens. Once the distal anastomosis is completed, intercostal arteries are reimplanted if necessary. 
From January 2014 to June 2020, we performed 17 replacements of the descending aorta with circulatory arrest for CBAD. Among these, we used transapical cannulation in six patients, including two who underwent emergency surgery for aortic rupture. No in-hospital death or major stroke occurred postoperatively (Table 1). No late deaths or aorta-related readmissions occurred during a mean follow-up period of 43 months.

\section{Discussion}

Although several reports have revealed the safety and durability of descending aorta replacement using deep hypothermic circulatory arrest, ${ }^{2}$ open surgery for CBAD has been shown to have considerable risks of cerebrovascular complications. ${ }^{3}$ Because retrograde perfusion is a potential cause of intraoperative cerebrovascular events, we apply transapical aortic cannulation for patients with poor vascular access, shaggy aorta, or partial thrombosis of the false lumen. Shiiya et al. ${ }^{4}$ reported a case of thoracoabdominal aortic repair with apical cannulation and stated that apical cannulation was advantageous in terms of preventing retrograde thrombotic events. Takemura et al. ${ }^{5}$ reported the usefulness of transapical cannulation to prevent malperfusion in the treatment of an acute traumatic descending aortic rupture. The advantages of transapical cannulation include antegrade perfusion, true lumen perfusion, and quick establishment of CPB. ${ }^{6}$ The apex is easy to expose and access via left thoracotomy, and a guidewire and cannula can be easily visualized with transesophageal echocardiography. Some surgeons establish CPB before thoracotomy in patients with aortic rupture. However, we safely canulated the apex and established CPB in two patients with aortic rupture. In those patients, we initially performed a small left anterior thoracotomy and extended the thoracotomy laterally after establishment of CPB.

Another advantage of apical cannulation is that the apical cannula can be used as a vent, as described above. Venting the ascending aorta during circulatory arrest with Takamoto's technique provides a bloodless operative field for the proximal anastomosis. Additionally, the apical cannula can be used as a left ventricular vent during rewarming by pulling it back to the left ventricle.

Although there are risks of apical bleeding and pseudoaneurysm after apical cannulation, a previous study showed low incidences of those complications, ${ }^{7}$ and secure surgical procedures can prevent them. ${ }^{8}$ No reexploration for bleeding or apical pseudoaneurysm occurred among our six patients.

In conclusion, apical cannulation is a useful option in open repair of the descending aorta for CBAD.

Conflict of interests: The authors have no conflicts of interest to declare.

\section{References}

1. Takamoto S, Okita Y, Ando M, Morota T, Handa N, Kawashima Y. Retrograde cerebral circulation for distal aortic arch surgery through a left thoracotomy. J Card Surg. 1994;9:576-82; discussion 582-3.

2. Corvera, J, Copeland, H, Blitzer, D, Hicks, A, Manghelli, J, Hess, P, et al. Open repair of chronic thoracic and thoracoabdominal aortic dissection using deep hypothermia and circulatory arrest. J Thorac Cardiovasc Surg. 2017; 154(2): 389-95.

3. Tian DH, De Silva RP, Wang T, Yan TD. Open surgical repair for CBAD: a systematic review. Ann Cardiothorac Surg. $2014 ; 3(4): 340-50$.

4. Shiiya N, Yasuda K, Murashita T, Suto Y, Kanaoka T, Matsui Y, et al. Transapical aortic cannulation for hypothermic aortic operation through a left thoracotomy: an alternative to avoid retrograde arterial perfusion. J Thorac Cardiovasc Surg. 1997;113:1113-4.

5. Takemura T, Shimamura Y, Sakaguchi M, Tsuda Y, Iwasa S. Transapical aortic cannulation using a deep hypothermic procedure through a left thoracotomy for acute traumatic aortic rupture. Jpn J Thorac Cardiovasc Surg. 2003;51:619-21.

6. Abe T, Usui A. The cannulation strategy in surgery for acute type A dissection. Gen Thorac Cardiovasc Surg. 2017; 65(1): 1-9. 
7. Wada S, Yamamoto S, Honda J, Hiramoto A, Wada H, Hosoda Y. Transapical aortic cannulation for CPB in type A aortic dissection operations. J Thorac Cardiovasc Surg. 2006;132:369-72.

8. Tabata M. Transapical approach in transcatheter cardiovascular interventions. Gen Thorac Cardiovasc Surg. 2018;66:185-91.

\section{Figure Legends}

Fig. 1. (a) Cardiopulmonary bypass is established by arterial cannulation via the apex and left femoral artery with venous drainage via the left femoral vein. (b) An apical cannula is used as a vent to ensure a bloodless operative field during proximal anastomosis. (c) The apical cannula is pulled back to the left ventricle and used as a ventricular vent during rewarming.

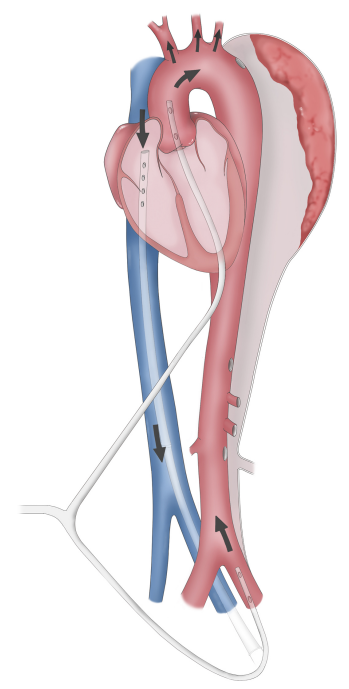

A

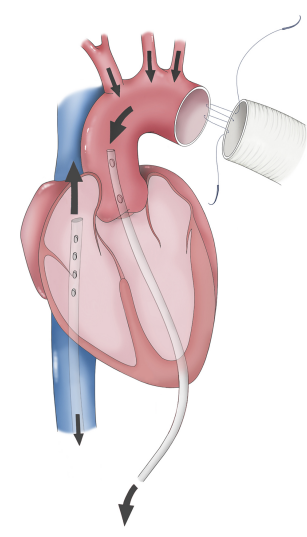

B

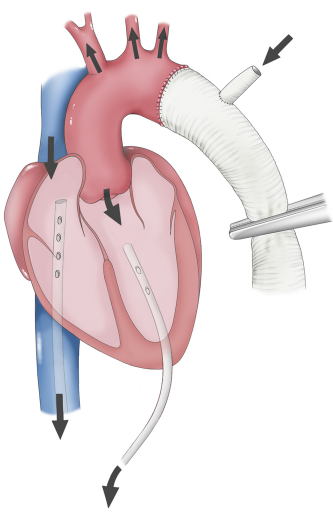

C

\section{Hosted file}

Table .docx available at https://authorea.com/users/449998/articles/548441-transapicalcannulation-for-surgical-repair-of-chronic-type-b-aortic-dissection 